\title{
Making Visible More Diverse Nature Futures through Citizen Science
}

\author{
GRADON DIPROSE (D)
}

ALISON GREENAWAY (D) BENJAMIN MOORHOUSE (D)

*Author affiliations can be found in the back matter of this article

\begin{abstract}
As the effects of the anthropocene continue, the presence and absence of birds has become a growing concern. Citizen science provides a way to collect data about birds and their locations while also building citizen engagement with biodiversity. Recent research on citizen science has highlighted the need to move beyond monitoring projects to understand the outcomes and impacts of citizen science for social-ecological systems. Researchers have explored how science constructs certain categories and ways of knowing, people's diverse participation experiences, and the potential changes in ecological systems as people shift their practices (or not) in response to citizen science. In this article, we draw on research from a citizen science initiative, the New Zealand Garden Bird Survey, to describe the self-reported outcomes for participants, and consequent impacts/actions for people and nature. We then use the Nature Futures Framework (NFF) to organise the outcomes and impacts to make visible the diverse values around nature that are expressed and fostered through the New Zealand Garden Bird Survey. We conclude by suggesting how citizen science can help mobilise action for more diverse nature futures.
\end{abstract}

\section{CORRESPONDING AUTHOR:}

\section{Gradon Diprose}

Manaaki Whenua Landcare Research, NZ

diproseg@landcareresearch. co.nz

\section{KEYWORDS:}

citizen science; biodiversity; New Zealand; birds; nature futures

TO CITE THIS ARTICLE:

Diprose, G, Greenaway, A and Moorhouse, B. 2022. Making Visible More Diverse Nature Futures through Citizen Science. Citizen Science: Theory and Practice, 7(1): 6, pp. 1-13. DOI: https://doi.org/10.5334/cstp.442 


\section{INTRODUCTION}

Recent work on citizen science (CS) has highlighted how it can be used to foster education and care about both nature and science (Dickenson et al. 2012; Ganzevoort et al. 2017; Richardson et al. 2020). As the impacts of the anthropocene intensify reflected in climate change (wildfires, rising temperatures, and extreme weather), biodiversity loss, habitat destruction, and COVID-19, research has also explored how nature contributes to human health and wellbeing (Nisbet et al. 2010; Sandifer et al. 2015). To date, most evaluations of CS projects have focused on monitoring outputs and data collection methods. This might include, for example, checking that participants are contributing the data needed in an appropriate way (i.e., they are following the correct protocols), that participants are happy taking part, that they have the necessary resources to do the required activities, and that they understand the outputs emerging from the project (Dickenson et al. 2012; Geoghegan et al. 2016). In other words, the focus has been somewhat instrumental in the sense of making sure citizens do it right, and stay doing it. Consequently, Geoghegan et al. (2016) suggest that along with monitoring of outputs, CS researchers also need to explore deeper evaluations of outcomes and impacts. The authors understand outcomes as learning and attitudinal changes, and impacts as behavioural and practice changes at individual and collective scales. Others go further, arguing that there is a need to better understand how CS connects to shifting social-ecological systems, including people's trust in science, institutions, and governance structures; social-ecological justice; and ultimately citizens' role in transformative change (Burke and Heynen 2014; Crain et al. 2014; Pereira et al. 2020; Togood 2013).

Pereira et al. (2020, p. 1173) suggest that fostering capacity for transformative social-ecological change "requires identifying visions, pathways and plans that can help people navigate away from undesirable futures and towards desirable ones." They argue that there is an urgent need to reframe human nature relations towards more diverse perspectives on what is desirable. Through the scenarios and models expert group of the Intergovernmental Science-Policy Platform on Biodiversity and Ecosystem Services (IPBES), Pereira et al. (2020) have developed the Nature Futures Framework (NFF). The NFF identifies three broad perspectives on human nature relations: nature for nature (understood as the intrinsic value humans attribute to nature); nature for society (understood as the instrumental benefits nature provides to humans); and nature for culture (understood as the relational connections between humans and nature). Pereira et al. (2020) suggest all three perspectives are important, and some may be prioritised over others at certain times and places. People might also find themselves in intermediate positions of the preference space where all perspectives coexist. The NFF is a heuristic tool that can be used to make visible the diverse, positive relationships that people already have with nature, while also providing an underlying structure for consistent scenarios and models for the future.

In what follows we provide a rich description of outcomes and impacts of the New Zealand Garden Bird Survey (NZGBS), an annual CS Winter bird count in Aotearoa New Zealand that is led by Manaaki Whenua-Landcare Research (MWLR). ${ }^{1}$ We build on previous NZGBS monitoring and evaluation (see Liberatore et al. 2018; MacLeod and Scott 2020), but shift focus to outcomes and impacts using a mixed method, but primarily qualitative analysis, approach. We show how outcomes (cognitive learning and affective nature experiences) are fostered through the NZGBS and how this prompts impacts (behavioural and practice changes) at individual and collective scales. Finally, we reflect on how the outcomes and impacts of the NZGBS can be organised using the NFF to make visible the existing diverse human-nature values that prompt participation in, and are expressed through, counting and reporting birds.

Section 1 situates the research foci and approach in the wider literature on critical CS. Section 2 provides background detail about the NZGBS and context. Section 3 summarises key outcomes and impacts of the NZGBS, and maps these using a NFF lens. Section 4 concludes by suggesting how these findings can inform other CS projects, specifically the value of using a NFF lens to make visible the diverse values people express through participation.

\section{CRITICAL CITIZEN SCIENCE}

In this article, we draw on Heigl et al. (2019), who suggest that a CS project involves a set of structured practices (often following a set protocol), undertaken by citizens (partly or fully), in which the results are communicated back to participants, and data are managed in ethical ways. There is something of a broad distinction in the literature between contributory (instrumentalist) CS and citizen-led dialogues about science, nature, and society (Dickenson et al. 2012; Shirk et al. 2012; Toogood 2013). Contributory CS tends to involve citizens gathering data using a protocol developed by experts for a question defined by experts. In contrast, citizen-led dialogues tend to be more open-ended, founded in ideas of agonistic democracy, debate, and citizen involvement in determining questions and the nature of participation. Toogood (2013) suggests that the majority of CS projects are based on a contributory model that 
tries to engage people in a scientific process in which the question, protocols, and outputs are primarily determined by professional scientists. Many of these projects focus on biodiversity, specifically identifying, counting, and mapping it (Bonney et al. 2015). While in practice some CS projects span the contributory-participatory-co-constructed model, some social scientists in particular have argued that CS has been dominated by physical/natural scientists who often neglect to consider how their processes shape the experience of participants, how different people are positioned, and what knowledge is privileged (Burke and Heynen 2014; Lambert et al. 2018; Toogood 2013).

Within the literature on contributory CS, research has tended to focus on the monitoring and evaluation of the process and outputs, including understanding motivations of participants, and how to recruit and retain them (Wehn and Almomani 2019). This research tends to be informed by theoretical frameworks emerging from psychology, management, volunteering, communication, and userexperience literature, which is then applied to CS. For example, the work of Clary and Snyder (1999) is often used to understand participant motivations for engaging in volunteer activities, which have then been applied to CS activities (see for instance Alender 2016; Dem et al. 2018; Jacobsen et al. 2012; Larson et al. 2020). Communication and user-experience research has focused on how CS projects and protocols are designed. For example, using online apps/platforms, providing adequate resources so participants can do what is asked of them, and ensuring the process is engaging through gamification, competition and recognition, or peer esteem feedbacks (see for instance Massung et al. 2013; Nov et al. 2014). This research often uses insights to inform the design, messaging, feedbacks, and protocols of particular CS projects to maximise recruitment and retention of participants.

Within the more critical citizen-centred research, there has been an emphasis from science and technology studies (STS) on the ways in which scientific knowledge is constructed. This work explores how science constructs certain categories, the skills needed to participate in legitimate science, and analysis of what knowledge is valued (Burke and Heynen 2014; Lorimer 2008; Togood 2013). Citizen-centred researchers have critiqued contributory CS for being top-down and driven by science experts who define the question, the nature of involvement, the analysis, and reporting of outputs (Burke and Heynen 2014; Toogood 2013). While contributory CS may seek and incorporate feedback from participants, this is done to encourage participation so that scientists will get the data they need. Critics of contributory and instrumentalist CS projects argue that monitoring research (i.e., we found these motivations were important, or we designed a new app/platform) rarely contributes to understanding the outcomes and impacts of CS, or empowers participants and communities to design their own questions and processes (Burke and Heynen 2014; Toogood 2013). Consequently, as Crain et al. (2014) argue, there is a need to push beyond contributory models and explore a wider range of CS outcomes and impacts on specific places.

In response to these critiques there is emerging work on co-produced CS in which participants partly shape the questions, co-construct the protocols, and use the results to address local, place-based problems or prompt new learning and action. This work often involves interdisciplinary research teams collecting ecological and social data to understand how coupled social-ecological systems intersect with debates about adaptive management and action for nature in specific contexts (see for instance Crain et al. 2014; Ganzevoort et al. 2017; Wehn and Almomani 2019). In what follows, we contribute to this emerging work by focusing on how participants experience their involvement in a contributory CS project, what this means to them, and how they use the data for their own varied purposes and actions to connect with wider matters of concern.

\section{CONTEXT}

Bird-based CS projects are some of the largest and most well known in the world. Many cultures have historic bird watching practices; birds are often charismatic species, are readily observable in many environments, and can serve as indicators of wider ecosystem changes (Sullivan et al. 2009). The NZGBS began in 2007 and was modelled on garden bird surveys in the northern hemisphere. People participate by counting the maximum number and type of birds they see or hear at one time in their gardens, local parks, and/or schools for one hour during a week in winter (Spurr 2012). Participants then upload their bird counts to an online form that records their observations against their location. In recent years, participants have also filled in a voluntary questionnaire about their demographic information and motivations for and experiences of participating. The idea behind the NZGBS is to convert people's individual bird counts into meaningful estimates of wider population changes over time. Counts from every garden surveyed are linked to their location within a neighbourhood, suburb, district, and region to calculate how bird counts change over 5- and 10-year timeframes at each of these spatial scales. ${ }^{2}$ The NZGBS has drawn on over 50,000 individual bird surveys since 2007 to calculate changes in 14 common garden bird populations nationally and regionally. The NZGBS has become the longest running annual national survey of biodiversity in Aotearoa New Zealand. 
Since 2007, participant numbers in the NZGBS have grown, with the highest number of people ever participating in 2020. ${ }^{3}$ In more recent years, there has been significant work on monitoring and co-developing the outputs from the NZGBS, such as reports, images, and education materials, to create and communicate the findings in meaningful ways $^{4}$ (see MacLeod et al. 2019a). From this monitoring, we know that making the NZGBS outputs visually appealing and accessible, coupled with the creation of a Facebook group (which functions as a community of practice), has led to increased uptake of results by mainstream media, local government, community groups, and individuals (see MacLeod and Scott 2020).

The NZGBS takes place within a wider ecosystem of human-nature debates and practices in Aotearoa New Zealand. These include other CS projects; education initiatives to connect people with nature; predator and pest control (primarily through the national Predator Free 2050 programme); government and philanthropic funding for collaborative-community landscape and place-based restoration projects (such as Reconnecting Northland and Cape to City); and an increasing focus on state-ofenvironment reporting (Parliamentary Commissioner for the Environment 2019), data sovereignty (Kukutai et al. 2020), and open data for improved democracy (Davies et al. 2019). There are also other bird-based CS and nature engagement projects in Aotearoa New Zealand, including Forest and Bird's Bird of the Year, The Great Kereru Count, The New Zealand Bird Atlas, and Bioblitz.

The Department of Conservation (DOC) has also developed resources that seek to prompt changes in nature-society relations to promote both environmental and human wellbeing. These include: National Connection to Nature Survey, 5 Pathways to Nature, and 50 Things to do in Nature (Department of Conservation, N.D.). DOC has promoted the NZGBS as an engagement activity that educators can use to help young people connect with nature and develop relevant action learning. Significantly, DOC partnered with MWLR to develop NZGBS-specific educational resources that connect to the New Zealand national school curriculum (Department of Conservation, N.D.).

These CS projects and environmental initiatives, the COVID-19 pandemic, and debates about how to restore nature and ensure human wellbeing in the anthropocene reflect different values and aspirations. However, they provide an important context for the NZGBS and naturesociety relations in Aotearoa New Zealand. We have observed in recent years how the NZGBS intersects with many of these other projects and debates. For instance, it is perhaps unsurprising that 2020 had the highest number of participants ever. While MWLR invested more resources in the NZGBS campaign, many people across Aotearoa New Zealand were increasingly focused on nature and particularly birds in their gardens and neighborhoods, owing to the pandemic response that restricted people's movements (see for instance; Doyle 2020; MWLR 2020; DOC 2020). As various Predator Free groups have formed around the country and landscape restoration projects have begun, MWLR have received inquiries from people who are keen to use the NZGBS data to monitor the value of these efforts. However, concerns have also been raised around the use and sharing of the NZGBS data as they become increasingly valued and requested. In the absence of other data and landscape-scale environmental monitoring, the NZGBS appears to be meeting a need, around which people coalesce for different reasons.

\section{METHODS}

We used a mixed-methods approach for this research that included:

- a review of previous research and data related to the NZGBS,

- semi-structured exploratory conversations with nine stakeholders,

- a large-scale participant feedback questionnaire undertaken in conjunction with the NZGBS in July 2020 ( $n=6746)$, and

- a focus group with eight participants (aged 8-16 years old).

The review of previous NZGBS research and data, and semi-structured exploratory conversations with nine stakeholders, helped identify existing knowledge and informed our focus on outcomes and impacts. The semistructured exploratory conversations were conducted with people who had either been previously involved in the NZGBS or were identified as having useful knowledge or feedback through snowball recruitment. These participants included staff and volunteers from environmental nongovernmental organisations, environmental educators, and local government community engagement and/or science staff. The conversations used topic questions as a guide, but the exact line of questioning differed in each case and depended on the role, positionality, and knowledge of the participant (Given 2008). The conversations were not recorded and have not been included in the results and discussion section that follows. We include reference to this discovery work here as part of our method because 
it helped us better understand the wider context in which the NZGBS is situated, and refine the design of the questionnaire and focus group.

The large-scale participant feedback questionnaire was included as part of the actual 2020 NZGBS. After NZGBS participants submitted their online bird counts in July 2020, they were directed to a voluntary SurveyMonkey questionnaire. The questionnaire asked for demographic information; participant motivations for taking part in the NZGBS; participant views and knowledge on birds and nature in New Zealand; personal outcomes and impacts of the NZGBS around learning; and the use/application of the NZGBS results. ${ }^{5}$ The questionnaire had a total of 6,746 responses, which equated to a response rate of $92 \%$ of the total submitted garden bird surveys. Reflecting our commitment to research methods that enable participants to determine their level of participation, most of the questions in the questionnaire were optional. The only compulsory question related to the number of people who participated in the NZGBS. In the results and discussion section, our analysis of the questionnaire focuses solely on one open-ended question related to learning. We do not undertake a quantitative analysis of the entire questionnaire, nor do we consider many of the usual discussions around quantitative methods such as bias or analysis via demographic categories. Our focus here is on how participants describe the learning outcomes and impacts in their own words. We therefore use a qualitative narrative approach that is grounded in a different epistemological understanding to quantitative data analysis (see Monroe et al. 2019).

To undertake the focus group, we partnered with DOC and the Porirua Community Collaboration Education Programme, a community-led place-based restoration project in Porirua involving young people. The focus group consisted of eight participants aged between 8 and 16 years of age who had completed the NZGBS in July $2020 .{ }^{\circ}$ We explored similar topics to the questions asked in the questionnaire. However, we used the focus group to explore narratives and meaning around

- who participants completed the NZGBS with (i.e., the sociality of the NZGBS practice);

- how participants felt during and after doing the survey (the experiential and affective);

- participants' existing knowledge about birds and whether they learnt anything new (cognitive knowledge);

- whether participants had questions resulting from their involvement; and

- participants' aspirations for nature in Porirua.
Ethics approval for the questionnaire and focus group was obtained through MWLR's social ethics process.

We analysed the open-ended question in the questionnaire and focus group data using an inductive thematic approach to group participants' self-reported outcomes (learning and attitudinal changes) and impacts (behavioural and practice changes). While we began the analysis process with an intention to focus on outcomes and impacts, we let the data determine the specific coding structure that emerged (Braun and Clarke 2006; Thomas 2006). We then organised the outcomes and impacts using NFF to illustrate the diverse values shaping participation in the NZGBS.

\section{DISCUSSION AND RESULTS}

In what follows, we firstly describe the key themes that emerged from the inductive thematic analysis of the open-ended question in the questionnaire, and within the focus group, in relation to self-reported outcomes and impacts. We then describe how the outcomes and impacts reflect pathways to a connection with nature (Lumber et al. 2017). We conclude with reflections on how the NFF can be used to make visible the diverse values that prompt participation in, and are expressed through, CS projects.

\section{OUTCOMES}

To understand some of the outcomes and impacts of the NZGBS, we asked participants in the questionnaire and focus group whether involvement helped them on their learning journey about birds. 6,165 participants responded to this question in the questionnaire (out of a total of 6,746 ), with $77.4 \%$ stating the NZGBS did help their learning journey. All participants in the focus group stated that the NZGBS did help their learning journey about birds. Figure 1 provides a breakdown of the responses from the questionnaire and the inductive analysis process we used to group responses into two broad outcome themescognitive learning and affective encounters with birds. We used the responses from both the questionnaire and the focus group to analyse and code into the self-reported outcomes and impacts.

\section{Cognitive learning}

Cognitive learning was the largest self-reported outcome, and we identified four sub-themes: bird identification; the NZGBS as a useful dataset; new knowledge about bird behaviour and needs; and the NZGBS as a useful education tool for others. 


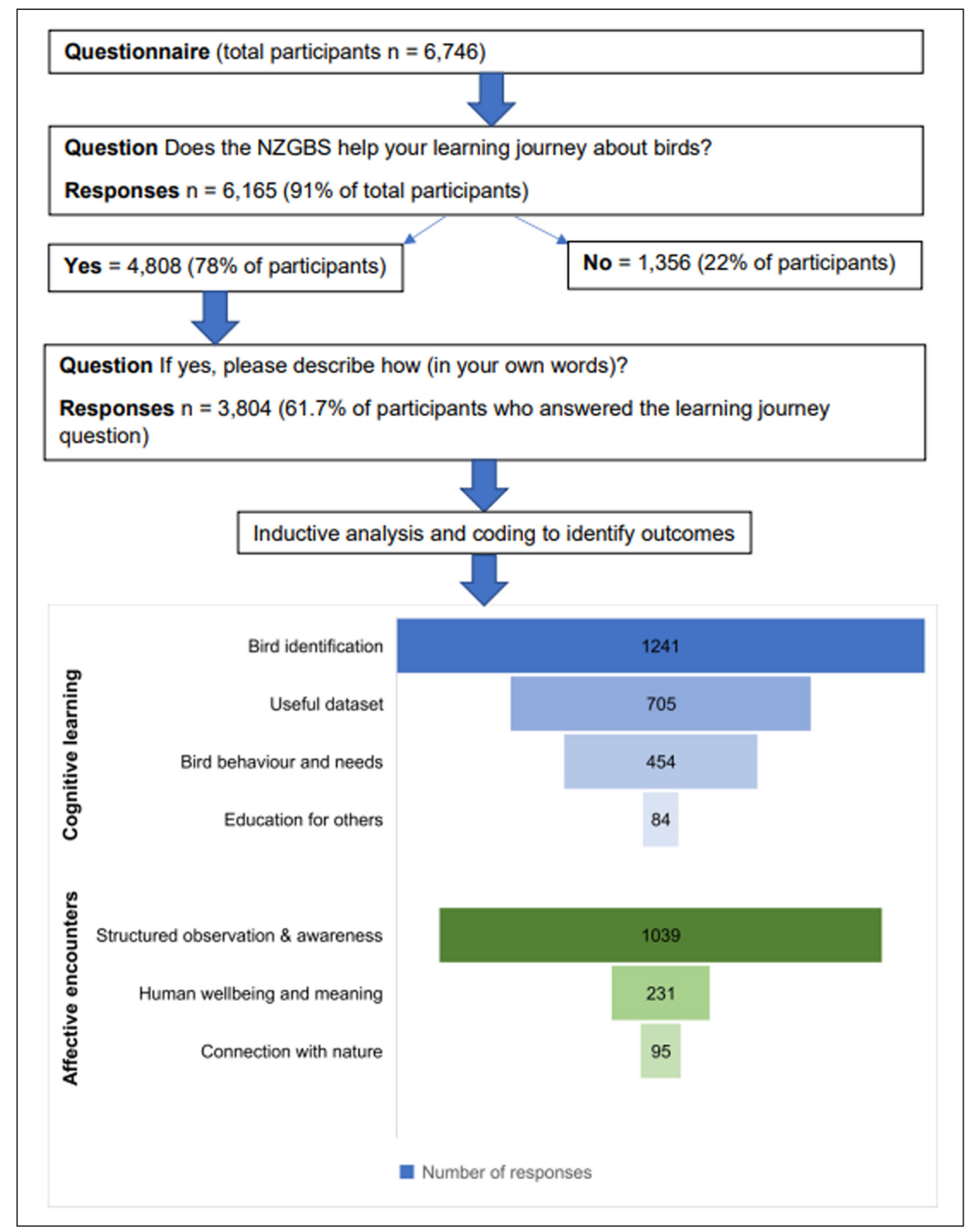

Figure 1 Self-reported outcomes and impacts from the New Zealand Garden Bird Survey (NZGBS) in terms of learning.

Improved bird identification was the highest reported cognitive outcome. 1,241 participants (or 32.6\% ${ }^{8}$ ) described how the NZGBS helped them to improve their ability to accurately identify birds, gave them a "good reason" to practice and improve their bird identification, and helped them to learn new names of species, including indigenous te reo Māori names. Participants noted how they used the NZGBS identification resources, as well as books, the internet, and other sources to help develop their bird identification knowledge. One participant noted,

"It made me find out how to identify the difference between mallards and grey and hybrid ducks. In looking that up, I saw lots of other birds and read up on some of them."

The second largest reported cognitive outcome related to the NZGBS dataset, with 705 participants (or 18.5\%) describing how it helped them develop new knowledge. Participants noted that the NZGBS dataset and yearly reporting of trends were "interesting," "informative," and helped them "understand" and "stay up to date" on national and regional trends in bird populations. Others described how they personally use their NZGBS counts to track and monitor changes of bird numbers in their garden or neighbourhood. Others noted how they use the NZGBS 
process and results to monitor the local impacts of their actions, including, planting, habitat restoration, feeding, and predator control efforts. One wrote,

"I have moved to a new home in the country and doing the survey gives me a baseline for birds that have territories where I am living. It gives me a snapshot of what is around me and then I can do my bit to improve things."

For some of these participants, particularly new migrants, the NZGBS was described as an important way to develop new place knowledge and attachments. For example, one participant wrote:

"I came to NZ two years ago, participating in this survey made me more aware of NZ garden birds."

For 454 participants (11.9\%), the NZGBS helped them develop new knowledge about bird behaviour and needs. This included what birds like to eat, how they interact (pecking order), what kinds of habitat they like, what regions/areas different species reside in, and the impacts of weather and daylight on birds:

"Has made me more aware of how different birds behave and watching how and what they feed on."

"Far greater awareness of the variety, numbers and feeding habits."

As with identifying birds, participants described how observing bird behaviour and needs prompted curiosity and further questions and research into specific questions. As one participant noted,

"It encourages me to find out more about birds and their habitats."

Finally, 84 participants (2.2\%) described how the NZGBS was a useful practice for educating others. These others included family members, young people and children, neighbours, and friends. Participants described how this happens in different ways, for example, through cognitive learning and ensuring one communicates the "correct information:"

"My partner did the survey with me and he learnt a lot about the variety of birds in our garden."

"I tell others about the survey (friends, family, neighbours). By informing others I have had to learn more about your survey and birds, so I pass on the correct information."

For some of these 84 participants, cognitive knowledge is less of a priority. Rather, the NZGBS is used to model and instil certain kinds of values and priorities to care for nature:

"Opens up conversations with my children about birds."

"Reminding my son of the importance of looking after the environment and wildlife."

"Reinforces how much I care about our native birds and pass it on to my grandchildren."

The results from the focus group reflected the questionnaire results, with all participants noting that they gained cognitive knowledge-specifically how to better identify birds through sight and sound. For some participants, the process of identifying birds led to questions and further research to better understand what birds need to survive well, including how human actions impact birds and nature. For example, participants queried where certain birds live in Porirua, whether birds prefer certain habitat, why they see some birds regularly and others less, and how weather affects birds. This then prompted reflections on the impact of local habitat restoration on specific bird species.

\section{Affective encounters with birds}

For 1,039 participants $(27.3 \%)$ the most important affective outcome was how the NZGBS fostered an experiential yet structured encounter between people and birds. Many of these participants noted the importance of just observing birds for a whole hour because it "fosters greater awareness," and requires people to "take notice" and be "more attentive." Participants described the effects of this affective encounter in different ways. For some, awareness was the key point; while for others, awareness led to feelings, knowledge, and new and renewed appreciations:

"Made us realise that there is greater diversity in our garden than we thought."

"Made me realise how much bird song is going on without even being aware of it."

"More attentive and appreciative of birds in my environment."

"Awareness leads to curiosity and knowledge." 
For 231 participants (6\%), the structured affective encounter led to some form of what we termed a wellbeing outcome. These included emotions, feelings, or states such as curiosity, joy, awe, fun, interest, wonder, a sense of connection, a sense of contribution, peacefulness, relaxation, and calm. Two articulations of this are:

"a good opportunity to slow down and tune into the activities of birds in the garden."

"Understanding and know how precious they [birds] are to our well-being."

For some of these 213 participants, contributing to the collective NZGBS effort fostered a sense of connection to other people in Aotearoa New Zealand who also value and care about birds:

"Makes me realise lots of people care about birds in Dunedin."

"I enjoy being part of a wider community's awareness of the value of bird life."

"Great sharing information and birdwatching pleasure with other like-minded kiwis."

"I become aware that care of birds is of national interest and importance and not just something I like in my garden.”

Finally, 95 participants (2.5\%) described how the NZGBS was a useful prompt and practice for connecting with nature:

"It makes me feel connected, it reminds me of the importance of the natural environment, it reminds me of the need for humans to care for the natural environment that we destroy every day, and as such I do more personal research on the ecology of NZ."

"Seeing them [birds] makes me feel connected to nature."

Participants in the focus group echoed these findings: Six of the eight participants described the NZGBS experience as "relaxing," with two stating that it made them feel "happy," that it prompted them to feel "in awe of the birds," and that they "loved it." These two participants shared how they completed the NZGBS together, making a picnic and taking turns to share the binoculars. The shared sociality of the activity, both with each other, and with birds, was key to their positive affective experience.

These findings illustrate how the NZGBS encourages participants to connect with birds and nature, and reflect pathways to nature connection research. Lumber et al. (2017) suggests that there are five affective pathways to connecting with nature: contact (using sense to engage); beauty (appreciation, aesthetics, wonder); meaning (nature and meaning, signs of nature); emotion (love, bond, feelings for nature); and compassion (extending the self to include nature, concern). Participants' accounts of the affective encounters fostered through the NZGBS reflect these five pathways where the structured observation prompts appreciation of birds' beauty, shifts in emotional states, compassion for birds, and, importantly, finding relational connection and meaning with other people through the collective effort of observing and counting birds.

\section{IMPACTS}

While impacts of CS are often difficult to quantify, data from the questionnaire suggest participants are acting and adapting their practices in response to the NZGBS. For instance, 336 questionnaire participants (8.8\%) selfreported behavioural and practice changes in response to the question about whether the NZGBS had helped their learning journey. They told us that:

- the NZGBS had prompted them to plant habitat,

- they now observe birds and nature more consciously and regularly,

- they now undertake bird counts more regularly,

- they are trapping predators, and

- they have started conversations about birds and nature with their neighbours and friends.

Some of these actions were more individual, such as participants planting trees or habitat in their gardens, while other actions were more collective, such as joining a local community group, or discussing bird-friendly habitat with their neighbours. Some wrote:

"Has encouraged us as a family to do more research and learn about our birds. We are planning on planting some native trees on our property to encourage more native birds."

"I'll be more inclined to look for opportunities to help in the community or find out about what local groups are doing. Help to engage my students by introducing these groups to our class attention." 
"Learnt I could do so much more by hooking up with community groups to trap predators and plant more bird friendly areas."

The NZGBS does not ask or suggest participants do anything other than count birds. However, our data suggest the practice of observing and counting birds both reflects and prompts nature connection, and then action for some participants. Reflecting findings on CS and learning outcomes (see Dickinson et al. 2012; Bonney et al. 2009), NZGBS participants are undertaking their own selfdirected learning and using the experience and datasets from the NZGBS for their own varied purposes, and in the process extending the NZGBS beyond the original contributory framing. Some participants see the NZGBS dataset as having value across different scales, providing not only national estimates of trends, but also important regional and local information that they use to monitor and track the impacts of their actions. Importantly, the individual and collective practices that people might enact following participation in the NZGBS come from their own interpretation of the results, personal research, and values. Following Lumber et al. (2017), we suggest that it is the combination of the cognitive knowledge and affective encounter fostered through the NZGBS that enables these diverse outcomes.

\section{THE NZGBS AND NATURE FUTURES FRAMEWORK}

In what follows, we use the NFF to illustrate how the NZGBS both reflects, and fosters, diverse understandings of, and aspirations for nature. In Figure 2, we have grouped research participants' stories about outcomes and impacts of the NZGBS using the NFF framework to illustrate how this CS project enables the expression of diverse values around nature.

Some NZGBS participants highlight the intrinsic value and beauty of birds (nature for nature). They describe how participation in the NZGBS reminds them of this intrinsic value, and the resourcing that goes into the dataset reflects this intrinsic value. Other participants highlight the

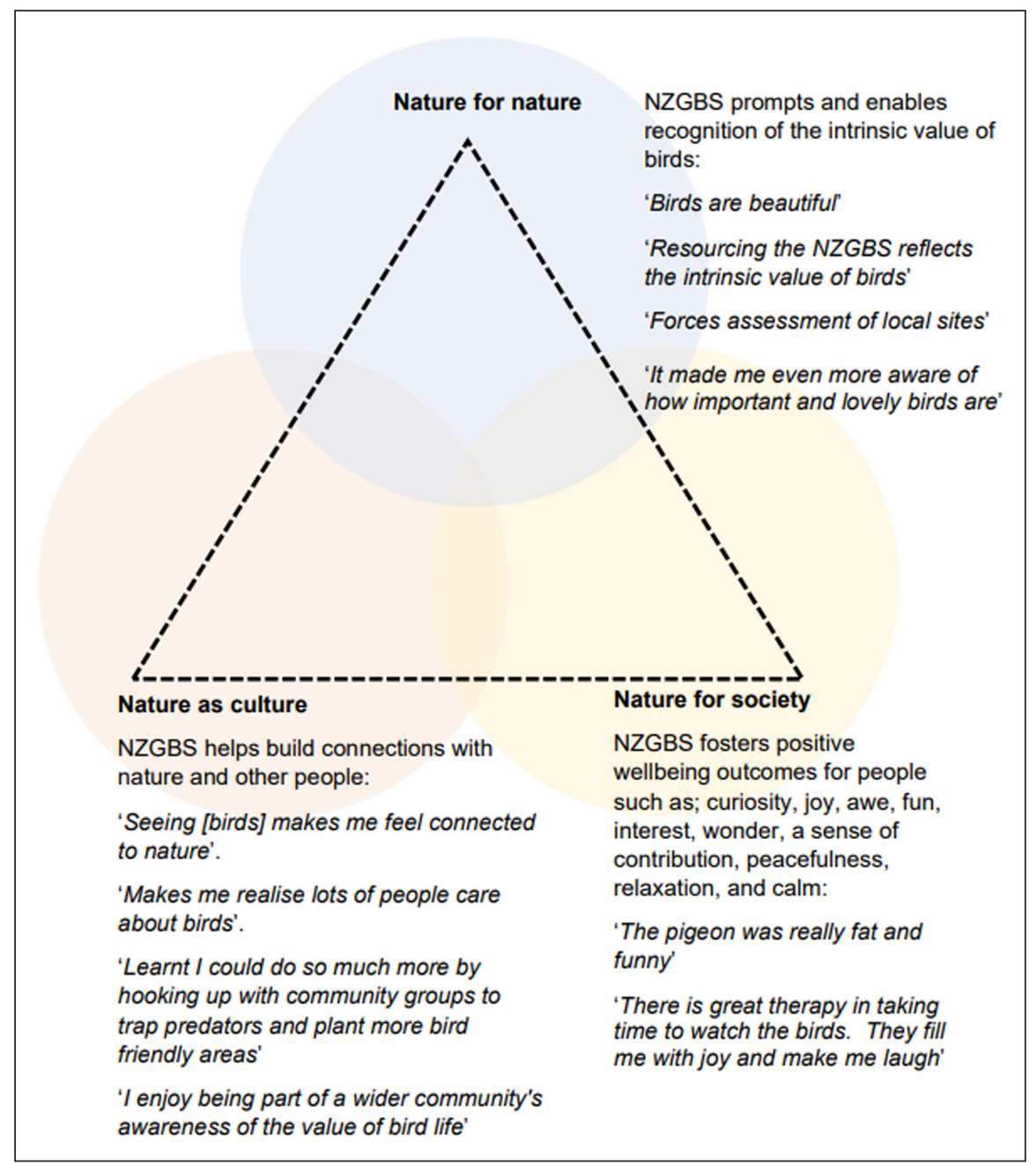

Figure 2 Values expressed and fostered through the New Zealand Garden Bird Survey (NZGBS) using a Nature Futures Framework. 
human wellbeing outcomes of doing the NZGBS (nature for society). These benefits included the emotional or affective experiences such as joy, amusement, feeling calm or relaxed, and being entertained and curious. Finally, other participants emphasised how observing and counting birds makes them feel connected to both nature and other people who care about these matters in Aotearoa New Zealand (nature as culture). Many of these participants emphasised how the NZGBS both reminded, and enabled them, to express care for nature in a collective effort that involved other people who share this value. Some of these participants talked about the importance of being part of this wider "movement that encompasses others with an interest in the continued well-being of birds," while others described how doing the NZGBS had helped them "connect" with other groups who were taking action for nature in specific places. In this way, the experience of doing the NZGBS was prompting some participants to make connections to place that are fostered by encounters with nature that went beyond participating in a CS project. The NZGBS does not require people to agree on, or to even articulate, a shared set of values before they can participate. Rather, through the collective practice of observing and counting birds, the NZGBS contributes to a wider network of people and groups who actively shape the valuing of birds across Aotearoa New Zealand.

\section{CONCLUSION}

In this article, we have used the NFF to make visible the diverse values around nature articulated through the NZGBS to widen the outcomes and impacts that might be considered in CS evaluations. For us, the NFF lens helps create greater space and visibility for the relational (nature as culture) aspects (S can foster-both between people and nature, and between people. Our sense is that CS projects and associated evaluations are good at theorising the values in the NFF related to nature for nature (science about nature) and to nature for society (ecosystem services and wellbeing benefits), but are less well equipped to evaluate nature as culture. Our view is that nature-based CS projects need to be able to accommodate all NFF perspectives to contribute to building the people-nature connection that is desperately needed to address the interconnected socialecological crisis of the anthropocene.

Throughout our analysis of outcomes and impacts, we have highlighted how participants shared stories of connection fostered through the NZGBS. This is about more than data (Moon et al. 2019). The NFF lens focuses our attention on whether and how CS can contribute to scaling out (but not necessarily up) a multiplicity of relationships and connections, and how to make these visible as part of evaluation processes. To support the transformation needed to address the climate and biodiversity crisis, CS projects can benefit from creating space for people to reflect on their relationships with both nature and other people. Our experience with the NZGBS suggests that this is best done through a connection approach, rather than emphasising only cognitive knowledge, or dictating how participants should manage pests and predators. As Crain et al. (2014) note, this connection may be done through the CS practice itself that encourages people to slow down, observe, and notice nature and their actions in place-especially the everyday environments people encounter and experience nature, like gardens, parks, and local greenspaces. Alternatively, this may be done through the CS evaluation process, in which participants are encouraged to reflect on the diverse outcomes and impacts that participating in a CS project have prompted. Focusing on connections and the relational makes visible the diverse ways people are already caring for and with nature in specific places, and is better able to reflect indigenous values and aspirations (Maclean et al. 2015; Lambert et al. 2018). Our analysis highlights how even within a contributory CS project like the NZGBS, shifting focus and asking different questions about outcomes and impacts reveals more diverse values and aspirations as related to nature.

\section{DATA ACCESSIBILITY STATEMENT}

The aggregated data from responses to closed-questions in the questionnaire is available upon request to the authors. The questions used in the questionnaire are also available upon request to the authors.

\section{NOTES}

1 Manaaki Whenua - Landcare Research is a Crown owned company mandated with carrying out scientific research on the management of terrestrial biodiversity and land resources for the benefit of New Zealand (Ministry of Business, Innovation and Employment, N.D.).

2 Specialised statistical tools are used to account for variation in sampling between regions, districts, and suburbs over time. Following bootstrap analysis and bias-correction of the modelled data, estimated trends in bird populations are summarised nationally and regionally according to their direction (decline or increase) and size (rapid to shallow) see MacLeod et al. (2019b) for further information.

3 While exact numbers of participants are difficult to quantify, our best estimates put participant numbers in 2020 at more than 8,268 people.

4 This has included: working with participants to create educational videos, bird identification kits, indigenous Māori bird name quizzes, findings reports, a Facebook group, and marketing and social media strategies. The emphasis on creating resources in the indigenous language of Aotearoa New Zealand (te reo Māori) forms 
part of wider strategies to connect rangatahi (Māori young people) with manu (birds) through nature.

5 We have chosen not to include a list of the questions in the questionnaire as part of this publication. Our questions were specific to the NZGBS and the history and context of this specific CS project and previous monitoring research. While our general analysis approach might be adaptable to other CS projects, the specific questions are not universally applicable. In our view, providing the exact questions perpetuates the unhelpful assumption that a social research method in one context is automatically appropriate to replicate elsewhere.

6 The two largest groups of people who participate in the NZGBS are women aged between 50 and 70 years old and people under 18 years old. We chose to focus on the 8-16-year-old age group for two reasons. Firstly, we hope to further build NZGBS engagement with this age group and felt the focus group would therefore provide useful insights. Secondly, we had access to willing participants and relationships in place that made an in-person focus group ethically possible in an uncertain COVID-19 context.

7 Constance and Roberts (2017) note that research on CS outcomes and impacts tends to adopt front-end formative and summative approaches to identify participants' existing knowledge, practices, and attitudes before being involved and then following involvement to identify any changes. We employed a similar approach by inviting participants to reflect on and self-report any changes. In the focus group, we employed more of a narrative approach that focused on "what" and "when" questions about specific experiences, rather than "how" and "why," which tend to result in abstract and generalised responses.

8 These percentages reflect the number of participants who described an outcome related to this theme as a proportion of the total number of participants who answered the open-ended question about how the NZGBS had helped their learning journey about birds.

\section{ETHICS AND CONSENT}

Ethics approval for the questionnaire and focus group was obtained through Manaaki Whenua - Landcare Research's social ethics process.

\section{ACKNOWLEDGEMENTS}

We would like to thank Angela Brandt, Nicolette Dellow, and Suzie Greenhalgh for feedback and input into the design and focus of this research. We are grateful to Anne Austin for editing the article. We are grateful to Rebecca McCormack for help in organising the focus group with young people from Porirua and would like to thank all the research participants for their input. Finally, we are grateful to two anonymous referees who provided helpful feedback and helped us clarify our contribution to citizen science.

\section{COMPETING INTERESTS}

The authors have no competing interests to declare.

\section{AUTHOR CONTRIBUTIONS}

GD and AG conceptualised the article. All authors contributed to the design of the methods, and GD and BM undertook data collection and analysis. GD coordinated drafting of the article, and all authors contributed to review and editing. All authors have read and agreed to the published version of the article.

\section{AUTHOR AFFILIATIONS}

Gradon Diprose (D) orcid.org/0000-0001-5394-9410

Manaaki Whenua Landcare Research, NZ

Alison Greenaway (D) orcid.org/0000-0003-2288-8621

Manaaki Whenua Landcare Research, NZ

Benjamin Moorhouse (D) orcid.org/0000-0002-6550-0415

Ministry for the Environment, NZ

\section{REFERENCES}

Alender, B. 2016. Understanding volunteer motivations to participate in citizen science projects: a deeper look at water quality monitoring. Science Communication, 15(3): 1-19. DOI: https://doi.org/10.22323/2.15030204

Bonney, R, Ballard, H, Jordan, R, McCallie, E, Phillips, T, Shirk, $\mathbf{J}$ and Wilderman, C. 2009. Public participation in scientific research: defining the field and assessing its potential for informal science education. Washington, DC: CAISE.

Bonney, R, Phillips, TB, Ballard, HL and Enck, JW. 2015. Can citizen science enhance public understanding of science? Public Understanding of Science, 21(1): 2-16. DOI: https://doi. org/10.1177/0963662515607406

Braun, $\mathbf{V}$ and Clarke, V. 2006. Using thematic analysis in psychology. Qualitative Research in Psychology, 3(2): 77-101. DOI: https://doi.org/10.1191/1478088706qp063oa

Burke, B and Heynen, N. 2014. Transforming participatory science into socioecological praxis: valuing marginalised environmental knowledges in the face of the neoliberalization of nature and science. Environment and Society: Advances in Research, 5(1): 7-27. DOI: https://doi. org/10.3167/ares.2014.050102

Clary, EG and Snyder, M. 1999. The motivations to volunteer: Theoretical and practical considerations. Current Directions in Psychological Science, 8(5): 156-159. DOI: https://doi. org/10.1111/1467-8721.00037

Crain, R, Cooper, C and Dickinson, J. 2014. Citizen Science: A Tool for Integrating Studies of Human and Natural Systems. Annual Review of Environment and Resources, 39: 641-665. DOI: https://doi.org/10.1146/annurevenviron-030713-154609 
Davies, T, Walker, S, Rubinstein, M and Perini, F. (eds). 2019. The State of Open Data: Histories and Horizons. Cape Town and Ottawa: African Minds and International Development Research Centre. DOI: https://doi. org/10.47622/9781928331957

Dem, E, Rodrigues-Labajos, B, Wiemers, M, Ott, J, Hirneisen, N, Bustamante, M and Settele, J. 2018. Understanding the relationship between volunteers' motivations and learning outcomes of Citizen Science in rice ecosystems in the Northern Philippines. Paddy and Water Environment, 16: 725735. DOI: https://doi.org/10.1007/s10333-018-0664-9

Department of Conservation. 2020. Mental health and key benefit to spending time outdoors. Available at https://www. doc.govt.nz/news/media-releases/2020-media-releases/ mental-health-a-key-benefit-to-spending-time-outdoors/ [accessed 28 April 2021].

Department of Conservation. N.D. Conservation Education. Available at https://www.doc.govt.nz/get-involved/ conservation-education/ [accessed 28 April 2021].

Dickenson, J, Shirk, J, Bonter, D, Bonney, R, Crain, R, Martin, J, Phillips, T and Purcell, K. 2012. The current state of citizen science as a tool for ecological research and public engagement. Frontiers in Ecology and the Environment, 10(6): 291-297. DOI: https://doi.org/10.1890/110236

Doyle, K. 2020. NZ's native birds thrive under Covid-19 lockdown. Radio New Zealand. Available at https://www.rnz.co.nz/news/ national/414232/nz-s-native-birds-thrive-under-covid-19lockdown [accessed 28 April 2021].

Ganzevoort, W, van den Born, R, Halffman, W and Turnhout, S. 2017. Sharing biodiversity data: citizen scientists' concerns and motivations. Biodiversity \& Conservation, 26(12): 28212837. DOI: https://doi.org/10.1007/s10531-017-1391-z

Geoghegan, H, Dyke, A, Pateman, R, West, S and Everett, G. 2016. Understanding motivations for citizen science. Final report on behalf of UKEOF, University of Reading, Stockholm Environment Institute (University of York) and University of the West of England.

Given, LM. (ed.) 2008. The SAGE Encyclopedia of Qualitative Research Methods (Volume 2). Thousand Oaks, CA: Sage Publications, Inc. DOI: https://doi. org/10.4135/9781412963909

Heigl, F, Kieslinger, B, Paul, KT, Uhlik, J and Dorler, D. 2019. Towards an international definition of citizen science. PNAS, 116(17): 8089-8092. DOI: https://doi.org/10.1073/ pnas.1903393116

Jacobsen, SK, Carlton, JS and Monroe, MC. 2012. Motivation and satisfaction of volunteers at a Florida natural resource agency. Journal of Park and Recreation Administration, 30(1): 55-67.

Kukutai, T, Carroll, SR and Walter, M. 2020. Indigenous data sovereignty. In Mamo, D (ed.), The Indigenous World 2020 (34th ed., pp. 654-662). Copenhagen, Denmark: IWGIA.
Lambert, S, Waipara, N, Black, A, Mark-Shadbolt, M and Wood, W. 2018. Indigenous biosecurity: Māori responses to Kauri Dieback and Myrtle Rust in Aotearoa New Zealand. In: Urquhart, J, Marzano, M and Potter, C (eds.), The Human Dimensions of Forest and Tree Health. Cham: Palgrave Macmillan. DOI: https://doi.org/10.1007/978-3-319-769561_5

Larson, LR, Cooper, CB, Futch, S, Singh, D, Shipley, NJ, Dale, K, LeBaron, GS and Takekawa, JY. 2020. The diverse motivations of citizen scientists: Does conservation emphasis grow as volunteer participation progresses? Biological Conservation, 242. DOI: https://doi.org/10.1016/j. biocon.2020.108428

Liberatore, A, Bowkett, E, MacLeod, CJ, Spurr, E and Longnecker, N. 2018. Social media as a platform for a citizen science community of practice. Citizen Science: Theory and Practice, 3(1): 1-14. DOI: https://doi.org/10.5334/cstp.108

Lumber, R, Richardson, M and Sheffield, D. 2017. Beyond knowing nature: Contact, emotion, compassion, meaning, and beauty are pathways to nature connection. PLOS One, 12(5): 1-24. DOI: https://doi.org/10.1371/journal. pone. 0177186

Maclean, $\mathrm{K}$ and The Bana Yarralji Bubu Inc. 2015. Crossing cultural boundaries: Integrating Indigenous water knowledge into water governance through co-research in the Queensland Wet Tropics, Australia. Geoforum, 59: 142-152. DOI: https://doi.org/10.1016/j.geoforum.2014.12.008

MacLeod, C and Scott, K. 2020. Mechanisms for enhancing public engagement with citizen science results. People and Nature, 3(1): 32-50. DOI: https://doi.org/10.1002/pan3. 10152

MacLeod, CJ, Howard, S, Green, P, Gormley, AM, Brandt, AJ, Scott, K and Spurr, EB. 2019a. NZ Garden Bird Survey 2017: data editing, analysis, interpretation, visualisation and communication methods. Manaaki Whenua Landcare Research Contract Report LC3461. Available at https:// datastore.landcareresearch.co.nz/dataset/nzgbs-2017-trendanalysis-and-reporting.

MacLeod, CJ, Howard, S, Gormley, AM and Spurr, EB. $2019 \mathrm{~b}$. NZ Garden Bird Survey 2018: data editing, analysis, and interpretation methods. Manaaki Whenua Landcare Research Contract Report LC3484 for the New Zealand Garden Bird Survey. Available at https://datastore.landcareresearch.co.nz/ dataset/nzgbs-2018-trend-analysis-methods.

Manaaki Whenua - Landcare Research. 2020. Slowing down enabled connection with nature. Available at https://www. landcareresearch.co.nz/news/slowing-down-enabledconnection-with-nature/ [accessed 28 April 2021].

Massung, E, Coyle, D, Cater, KF, Jay, M and Preist, C. 2013. Using Crowdsourcing to Support Pro-environmental Community Activism. Proceedings of the SIGCHI Conference on Human Factors in Computing Systems, 371-380. DOI: 
https://doi.org/10.1145/2470654.2470708

Ministry of Business, Innovation and Employment. N.D. Crown Research Institutes. Available at https://www.mbie.govt.nz/ science-and-technology/science-and-innovation/agenciespolicies-and-budget-initiatives/research-organisations/cri/ [accessed 28 April 20210].

Monroe, M, Adams, AE and Greenaway, A. 2019. 'Considering research paradigms in environmental education'. Environmental Education Research, 25(3): 309-313. DOI: https://doi.org/10.1080/13504622.2019.1610863

Moon, K, Adams, VM and Cooke, B. 2019. Shared personal reflections on the need to broaden the scope of conservation social science. People and Nature, 1(4): 426-434. DOI: https:// doi.org/10.1002/pan3.10043

Nisbet, E, Zelenski, J and Murphy, S. 2010. Happiness is in our nature: exploring nature relatedness as a contributor to subjective wellbeing. Journal of Happiness Studies, 12(2): 303-322. DOI: https://doi.org/10.1007/s10902-010-9197-7

Nov, 0, Arazy, 0 and Anderson, D. 2014. Scientists@Home: What drives the quantity and quality of Online citizen science participation? PlosOne, 9. DOI: https://doi.org/10.1371/ journal.pone.0090375

Parliamentary Commissioner for the Environment. 2019. Focusing Aotearoa New Zealand's environmental reporting system. Available at https://www.pce.parliament. $\mathrm{nz} /$ publications/focusing-aotearoa-new-zealand-senvironmental-reporting-system [accessed 28 April 2021].

Pereira, L, Davies, K, den Belder, E, Ferrier, S, Karlsson-Vinkhuyzen, S, Hyejin, K, Kuiper, J, Okayasu, S, Palomo, M, Pereira, H, Peterson, G, Sathyapalan, J, Schoolenberg, M, Alkemade, R, Ribeiro, S, Greenaway, A, Hauck, J, King, N, Lazarova, T, Ravera, F, Chettri, N, Cheung, W, Hendriks, R, Kolomytsev, G, Leadley, P, Metzger, J-P, Ninan, K, Pichs, R, Popp, A, Rondinini, C, Rosa, I, van Vuuren, D and Lundquist, C. 2020. Developing multiscale and integrative nature-people scenarios using the Nature
Futures Framework. People and Nature, 2(4): 1172-1195. DOI:

https://doi.org/10.1002/pan3.10146

Richardson, M, Passmore, H, Barbett, L, Lumber, R, Thomas, R and Hunt, R. 2020. The green care code: How nature connectedness and simple activities help explain pro-nature conservation behaviours. People and Nature, 2(3): 821-839. DOI: https://doi.org/10.1002/pan3.10117

Sandifer, P, Sutton-Grier, A and Ward, B. 2015. Exploring connections among nature, biodiversity, ecosystem services, and human health and well-being: Opportunities to enhance health and biodiversity conservation. Ecosystem Services, 12: 1-15. DOI: https://doi.org/10.1016/j.ecoser.2014.12.007

Shirk, J, Ballard, H, Wilderman, C, Phillips, T, Wiggins, A and Jordan, R. 2012. Public participation in scientific research: a framework for deliberate design. Ecology and Society, 17(2): 29. DOI: https://doi.org/10.5751/ES-04705-170229

Spurr, E. 2012. New Zealand Garden Bird Survey - analysis of the first four years. New Zealand Journal of Ecology, 36(3): 1-13. https://newzealandecology.org/nzje/3043.pdf.

Sullivan, BL, Wood, CL, Iliff, MJ, Bonney, RE, Fink, D and Kelling, S. 2009. eBird: A citizen-based bird observation network in the biological sciences. Biological Conservation, 142(10): 2282-2292. DOI: https://doi.org/10.1016/j. biocon.2009.05.006

Thomas, D. 2006. A General Inductive Approach for Analyzing Qualitative Evaluation Data. American Journal of Evaluation, 27(2): 237-246. DOI: https://doi.org/10.1177/1098214005283748

Toogood, M. 2013. Engaging publics: biodiversity data collection and the geographies of citizen science. Geography Compass, 7(9): 611-621. DOI: https://doi.org/10.1111/gec3.12067

Wehn, $\mathbf{U}$ and Almomani, A. 2019. Incentives and barriers for participation in community-based environmental monitoring and information systems: A critical analysis and integration of the literature. Environmental Science and Policy, 101: 341 357. DOI: https://doi.org/10.1016/j.envsci.2019.09.002

\section{TO CITE THIS ARTICLE:}

Diprose, G, Greenaway, A and Moorhouse, B. 2022. Making Visible More Diverse Nature Futures through Citizen Science. Citizen Science: Theory and Practice, 7(1): 6, pp. 1-13. DOI: https://doi.org/10.5334/cstp.442

Submitted: 02 May 2021 Accepted: 28 December 2021 Published: 24 February 2022

\section{COPYRIGHT:}

(C) 2022 The Author(s). This is an open-access article distributed under the terms of the Creative Commons Attribution 4.0 International License (CC-BY 4.0), which permits unrestricted use, distribution, and reproduction in any medium, provided the original author and source are credited. See http://creativecommons.org/licenses/by/4.0/.

Citizen Science: Theory and Practice is a peer-reviewed open access journal published by Ubiquity Press.

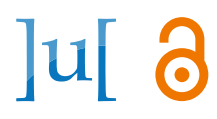

